Article type : Regular Article

\title{
Issues facing families of infants discharged after cardiac surgery: the perceptions of charity helpline staff
}

\author{
Jo Wray ${ }^{a}$, Jenifer Tregay ${ }^{a}$, Catherine Bull ${ }^{a}$, Rachel L. Knowles ${ }^{b}$, Sonya Crowe ${ }^{c}$ and \\ Katherine Brown ${ }^{\mathrm{a}}$
}

a Critical Care and Cardiorespiratory Department, Great Ormond Street Hospital for Children NHS Foundation Trust, London UK;

${ }^{b}$ MRC Centre of Epidemiology for Child Health, UCL Institute of Child Health, London, UK;

${ }^{c}$ Clinical Operational Research Unit, University College London, London UK

Corresponding author:

Dr Jo Wray

Great Ormond Street Hospital for Children NHS Foundation Trust

Room 4052, Barclay House (Level 4)

37 Queen Square

London, WC1N 3BH

+44 (0)2078297822

Email: jo.wray@gosh.nhs.uk

Short title: Families of infants discharged after heart surgery

This article has been accepted for publication and undergone full peer review but has not been through the copyediting, typesetting, pagination and proofreading process, which may lead to differences between this version and the Version of Record. Please cite this article as doi: 10.1111/apa.14304

This article is protected by copyright. All rights reserved. 


\section{Abstract}

Aim: To elicit the perceptions of helpline staff who talk to parents of children discharged after cardiac surgery in infancy about parents' key concerns.

Methods: A qualitative study involving semi-structured interviews with 10 staff at four heart charities. Interviews were recorded, transcribed and analysed using Framework analysis.

Results: Staff identified the knowledge, communication and support needs of parents which they described in terms of the impact of patient and family factors, sources of support and systems. Staff perceptions of helplines, in terms of the function of a helpline and the roles of its staff, together with staff's personal views based on their experience of multiple encounters with many families, influenced how they viewed families' needs and responded to their requests.

Conclusion: Helpline staff provided important, previously un-captured evidence about the challenges faced by parents of children discharged after cardiac surgery in infancy. Staff have an important role in supporting communication, in terms of speaking to families about how to talk to professionals and talking to professionals directly to get or give information when parents are unable to do so.

Capturing the perspective of helpline staff about communication issues has highlighted the need for interventions with professionals as well as parents.

\section{Key Notes}

1. Charity helpline staff support parents of ill children but their perceptions about parents' key concerns following their infant's hospital discharge after cardiac surgery have not been elicited previously

This article is protected by copyright. All rights reserved. 
2. Interviews with helpline staff highlighted that parents have significant knowledge, communication and support needs

3. Helpline staff have an important role in supporting and facilitating communication between parents and professionals but communication interventions are needed for both professionals and parents

\section{Background}

There are currently approximately 160,000 charities in the United Kingdom (UK), many of which have a focus on health, either generically or linked to specific diseases or conditions. Charities have a key role to play in providing support, information and practical assistance to patients with a diverse range of health conditions and their families, as well as providing specialized medical care in some instances. Some charities may employ health professionals to deliver medical care or specific medical advice whilst others may predominantly be staffed by volunteers who have no specific medical training but who are able, with appropriate training, to offer advice about practical concerns such as how to access financial assistance. All volunteers will receive training about how to listen to and talk to callers and when they should direct them to seek help from a medical professional. As part of the service they provide many charities run a telephone helpline and there is evidence (predominantly in the field of cancer) that patients and their carers/families rate these helplines positively in terms of information provision and reducing anxiety (1). Furthermore, it has been suggested that helplines fulfill a different function to websites, with website users less likely to request information on sensitive topics than helpline users but more likely to request factual information (2). Helplines offer callers anonymity, time to discuss their concerns and convenience. They are also available to other people indirectly affected by a condition, such as family members and friends (3). However, previous research into the role of helplines in health care, including those staffed by health professionals, has focused on the user perspective (for example collecting information about 
the usefulness of helplines in the provision of patient information or user views on staff communication skills), involving interviews or surveys with callers $(4,5)$ or on analysis of the content of recorded telephone conversations $(6,7)$, rather than on the perspectives of those who deliver the information or support. Helpline staff can provide a unique insight into why people call a helpline which is not specific to, or influenced by, individual hospital policies or health care practices, particularly as callers may be from anywhere in the country and can remain anonymous.

Congenital heart disease (CHD) is one of the most common birth defects, with an incidence of 8 per 1000 live births (8), and more than a third will require surgery in infancy (9). Paediatric cardiac surgery for children in the UK is commissioned nationally and is undertaken in 11 specialist paediatric cardiac surgical centres. Following surgery, children are discharged home and for those who have the most complex conditions this may be via their local (secondary care) hospital. Children are likely to receive at least some of their outpatient follow-up at the specialist (tertiary) centre but may also be followed-up in specialist outreach clinics locally. Individual specialist paediatric cardiac surgical centres will have a network of local hospitals whom they link with, largely determined by geography. Most children will have a named paediatrician at their local hospital and all children should have a general practitioner (GP) and, if they are under 5 years old, a health visitor (a nurse or midwife who has received additional specialist training).

There is a wealth of evidence about the psychological impact of the diagnosis of CHD and subsequent treatment on parents (10-14) but far less is documented about the specific concerns of parents once their child is discharged from hospital. As part of a larger study looking at infants with complex CHD who have been discharged home, which included interviews with parents and health professionals (15-21), we wanted to interview helpline 
staff from a number of charities providing support to families of children with CHD to understand their experiences of talking to families whose baby had recently been discharged after infant cardiac surgery. We specifically wanted to elicit their perceptions of the key reasons/issues/concerns that families called the helpline to discuss in relation to their baby's cardiac surgery.

\section{Methods}

\section{Setting}

The Children's Heart Federation (CHF) is a parent-led national charity which acts as the umbrella organisation for more than 20 other organisations and charities providing support to children with heart conditions and their families in the UK. The CHF has links to more than 12000 families of children with CHD and provides support via its website, email and a telephone helpline. Three of the national charities affiliated to the CHF are Little Hearts Matter, which specifically supports children with single ventricle conditions and their families, the Down's Heart Group which offers support and information relating to heart conditions associated with Down syndrome and Max Appeal! which supports families affected by 22q11.2 deletion (which may be associated with a congenital heart lesion). These charities between them therefore support families of children with a range of generic and individual congenital heart conditions.

\section{Procedure}

The Children's Heart Federation, Little Hearts Matter, Down's Heart Group and Max Appeal! were approached about participation. Each charity was provided with written information about the project and asked to pass this on to their helpline staff. If staff were willing to participate in an interview the charity provided the research team with contact details for the 
staff member and arrangements were made to conduct the interview either face to face or by telephone. All participants were assured of anonymity in the reporting of anything they told us and it was made explicit that we were not asking them about their responses to any issues raised by families but rather were interested in what the families told them. We aimed to recruit 8-12 participants, with at least one participant from each of the four charities.

All interviews were semi-structured and followed a topic guide. Interviews focused on the following areas:

- Families' concerns when they are initially discharged

- The information families are given by health professionals about their child's condition, what to look for and who to contact if they are worried

- Support that families access in the community

- Barriers to families getting the support they need

Participants were asked to provide either written or verbal consent concerning their participation in the study. All interviews were tape recorded (with participants' agreement) and transcribed verbatim (with all identifying information removed).

\section{Analysis}

The Framework approach (22) was used to analyse the data, which involves five distinct though highly interconnected stages: familiarisation; identifying a thematic framework; indexing; charting; mapping and interpretation. During the analysis a series of "frameworks" or grids was constructed, into which the summarised qualitative data and individual quotes 
were entered under descriptive headings. Members of the core research team worked collaboratively and iteratively to generate and agree the descriptive headings after careful reading of the transcripts. Data from each transcript were then individually entered into the framework and key themes were extracted from the completed frameworks and the relationships between the themes explored. Framework was selected as an approach to analyse the data because it is particularly well suited to multiple researchers being involved in the analysis process

Ethical approval for the study was granted from the local NRES Committee London -Central (Reference: 12/LO/1398).

\section{Results}

\section{Participants}

The charities each had 4-8 people working on their helpline and 12 helpline staff were given information about the study and agreed to participate, 10 of whom were interviewed. (9 female, 1 male; age range: 27-56 years). Eight participants were paid employees of one of the charities, one of whom had a relevant clinical professional background, and two participants were parent volunteers. Participants had worked on the helpline for between 1 and 15 years (median: 4.5 years). Two further helpline staff, both of whom were parent volunteers, agreed to participate but were unable to for logistical reasons. All of the participants had received training from their charity about how to deal with calls to the helpline and when it was appropriate to offer advice or provide information and when it was appropriate to refer the caller for specialized medical advice.

This article is protected by copyright. All rights reserved. 


\section{Interviews}

Five interviews were held face to face and 5 were conducted as telephone interviews.

Interviews lasted between 22 and 45 minutes (median: 35 minutes).

\section{Findings}

Participants believed that callers to the helpline had significant knowledge, communication and support needs after their babies were discharged from hospital, and that these needs were influenced by patient and family factors, sources of support and systems factors. The personal views of helpline staff based on their experience of multiple encounters with families influenced how they perceived families' needs, and their perceptions of the roles of both helpline staff and the helpline itself influenced how they responded to requests from families calling the helpline (Figure 1).

\section{Knowledge, communication and support needs}

Helpline staff described three key areas related to the core theme of knowledge, communication and support which parents called the helpline about. These three areas were practical issues, emotional issues and signs and symptoms.

\section{Practical issues}

Staff described calls requesting direct support or advice about accessing support in relation to practical topics such as feeding:

"We have them phoning up about feeding - feeding is a VERY big issue. It is incredibly stressful and families feel very responsible." [06]

This article is protected by copyright. All rights reserved. 
One staff member specifically spoke about the equipment requirements for tube feeding at home and described how some families are sent home without the correct equipment:

“So if they're trying to do an NG feed and you know it's a gravity feed-or even if they're on a pump - they don't provide a stand for the gravity feed or the pump. So how are you supposed to do an overnight on a pump without a stand? ... sometimes basic pieces of equipment are missing." [07]

A number of staff mentioned that they can provide families with small grants for medical equipment to support them caring for their children at home, such as INR [international normalized ratio] machines, and that they receive many calls from nurses as well as families about this. One helpline staff member specifically talked about the advice that some parents were given about looking out for signs and symptoms in their baby but not necessarily knowing how to do so and how the charity supports the family by funding the equipment they need to monitor their baby.

"We have in the past supplied pulse oximeters because bizarrely the hospitals like the families to look at the child and see how the child is looking. So "look at your baby and learn to know your baby, are they blue around the lips are they sweaty on the head, are they breathless, is their pulse racing?" Whereas if you're a qualified nurse or a consultant cardiologist then you use a pulse oximeter, but parents are encouraged not to do so - ironic isn't it? But the parents are supposed to look at their baby and know them from their colour and behaviour." [04]

Other practical issues included the logistical challenges that families faced in terms of support with childcare for siblings or a need for financial support.

"We do get calls, especially single families, who have other siblings, who are very worried about how to cope with child care arrangements and financially when they

This article is protected by copyright. All rights reserved. 
are taking time off work to care for their child, especially if they are in more isolated communities and don't necessarily have any kind of support." [03]

\section{Emotional issues}

As well as receiving calls about particular queries and concerns, helpline staff discussed calls that they received which were about the support needs of the family related to more general issues such as confidence and isolation. Several participants also talked about the psychological and emotional impact of congenital heart disease and subsequent treatment on parents of affected children and the need for parents to feel able to access support for themselves.

"They [parents] are very overly aware, highly vigilant and very anxious..... think what people really want when they phone us up is support, they want help, they want a face, they want somebody who can tell them it's going to be ok or can tell them this is what is going to happen, this is what you can expect, or even just somebody to say "I understand, I will listen to you" or "I don't understand, but tell me." They just want someone to talk to." [03]

Some participants talked about their perceptions of what helped or hindered parents in terms of their support networks:

"I think it depends a lot on how they are coping themselves, what family support network they have because obviously if you have got a good supportive family that are all rallying around... you know if you are a single family with no support then you have complete isolation." [08]

This article is protected by copyright. All rights reserved. 


\section{Signs and symptoms}

Parents frequently used the helpline as a means of accessing support and information to enable them to make a judgement about specific signs and symptoms they were concerned about, particularly soon after hospital discharge.

"We also get a lot of calls from people who have had recent discharges and they are very worried about even the slightest thing so they are not sure- I don't want to say they are paranoid because that sounds negative .......Totally understandably but they are like "Like oh my god I don't know if my child's lips are blue. How blue is blue. I don't know what you are talking about." [03]

Furthermore, some participants mentioned calls from parents unsure about what to look for which were not in response to a particular situation but were reflecting their more general anxiety about caring for their baby after being discharged from hospital.

"A lot of them are concerned about symptoms to look out for. So we get lots of calls from specifically mums or dads who've got home from the hospital who have been given lots of information but feel very lost so their questions is usually 'what should I do if', 'What should I look out for'." [04]

Some helpline staff also expressed their concerns about parents' lack of knowledge about signs and symptoms and what to look for.

"They'll go home with all the information about the medication for their children and they know exactly when they should be giving them and how much but they don't know why. They don't understand that if a child vomits what their next action should be regarding the medication they've given. They don't understand the signs and symptoms they need to be looking for so that they can trigger a concern with someone else - they don't understand about the respirations, they don't understand

This article is protected by copyright. All rights reserved. 
about the colour, the way the baby feeds, because we all know that feeding for cardiac babies gives you a whole history." [06]

\section{Factors perceived to be impacting on parents' needs}

\section{Patient and family factors}

The area in which staff expressed the strongest personal views about families was in relation to socioeconomic and cultural factors such as language barriers, educational level and financial difficulties. A number of staff described the challenges faced by families for whom English is not their first language:

"Discharge information needs to be given in the language that they understand otherwise they're never going to get it are they?" (06)

Some also described some of the struggles faced by parents from ethnic minorities and how poorer levels of education resulted in greater difficulties for families:

"And the ethnic communities like that can be quite difficult - they are really hard to reach. There are a lot of pressures.... we have a mum who had a child with a very complex heart defect who for a number of years .... her family .......really almost banned her from taking any outside help. And it's the cultural barriers that's probably the greater issue (rather than language barriers)". (07)

Parents with less education and fewer financial resources were felt to be quite disadvantaged in terms of their ability to plan and access medical care for their child:

"They couldn't afford to get from A to B and going back for their follow-up appointments. Subsequently they weren't able to make the appointments.....It does tend to be the less educated end that manages it worse because they don't think

This article is protected by copyright. All rights reserved. 
ahead, generally, to write things down or write questions down in advance or write what they have been told." (02)

Other staff went further in talking about the cultural barriers that some parents have to deal with to access support and the 'risks' they are willing to take in order to access support from the helpline:

\begin{abstract}
"You get people from minority backgrounds who will ... in their communities hold back from accessing support so perhaps wouldn't necessarily phone a charity, wouldn't go to find a support group. They wouldn't feel that that is acceptable in their own community. We have people we are in contact with who have a child with an illness and they are disowned from their community and find it very difficult to know where to go. It all comes down to when they are leaving the hospital, if they aren't given the information then they may never find it....so yes, there is definitely a big gap depending on their background." (01)
\end{abstract}

\title{
Sources of support
}

Participants described the individual sources of support that families access or call to discuss, such as health professionals in primary, secondary and tertiary care as well as nonprofessional support such as social media, other families and charities. Most participants talked specifically about the role of the cardiac liaison nurse (CLN), with both good and poor examples of how the role worked in practice.

"The ones that had clear access to a CLN or something similar seemed to do best because at least they could go back and ask." (02)

This article is protected by copyright. All rights reserved. 
"What a lot of parents find very useful is where...the CLN has been able to talk and support the parent in the handover to the community team - and some are better at that than others." (05)

"What I'm always shocked at is that some of them aren't even aware they have the CLN as that point of contact...When I contact the nurses on behalf of the family they're amazing - they give a lot of their time, they will speak for a long, long time and give me a very detailed response, but I just think that families aren't aware of them being there." $(01)$

Staff also commented on the varying levels of knowledge of, and support provided by, health professionals in the community and at the local hospital.

"You might get luck and have a GP that is tuned in, switched on, proactive, or you might get one that isn't really bothered. Sometimes you're at the mercy of a belligerent receptionist...lack of personalised GP support is so poor.” (07)

It was evident that staff felt there was a certain amount of chance in terms of the support and the quality of the service that families received, with a strong sense that families were often likely to receive inadequate support and/or services from community professionals, although it was not always clear whether it was the support or the service that the staff felt was inadequate:

"There is the occasional fantastic HV [health visitor] and the occasional fantastic GP and it would be terrible to tar them all with the same brush. But in most cases they are out of their league with knowledge base. They don't understand.” (06)

This article is protected by copyright. All rights reserved. 
As well as discussing support provided by health professionals the importance of nonmedical support was discussed, and in particular the unique role that other heart families have in providing support, either individually or as part of a parent support group:

"So to meet another Mum, to be given those opportunities, to be one-on-one or in a group. I think it's just invaluable. Just talking it through with someone." (01)

"They wanted to chat to families that would get the worries that they were going through and maybe see people that had already been through that and were already on to the next stage and how you can come through that and any tips they had to help each other." (10)

The role of social media for connecting people and helping to reduce social isolation was also identified by several staff:

"I think a lot of the parents are quite lonely. So they feel quite alone and that's where social media has come in because you often see things posted on Facebook and so on....you see questions and that sort of thing so they get support that way. They can build up friendships. (05)

\section{Systems and processes}

The third factor perceived to influence family need focused on the systems and processes, in terms of the content, format and quantity of information provided, knowing the network and people who should be providing support to parents, together with barriers to obtaining support and the consequences of that. The overarching theme was consistency and continuity - or conversely, the individual approaches in each centre, each community and of 
each professional, with the result that helpline staff perceived families to have very different experiences of 'the system' and how it works. This lack of consistency was perceived to extend across the network, from the tertiary centres and into primary and secondary care, and staff identified the need for a more joined up and coordinated approach to care for individual families. Some staff specifically described the variability in how information and support were provided for families:

"I don't know how that information is given in all centres. So that might vary. I think it's been varied..... some people come out feeling quite informed and others don't..... (02)

Others talked about the relationships and communication between professionals in tertiary and secondary/primary care and how this has a direct impact on the family:

"I think the quality of the CLN team and the quality of their relationships with external care providers ...that really fuels whether somebody will receive that support." (03)

"We get some patients who go into their GPs a couple of weeks later and the GP hasn't even got a letter so they don't even know what surgery the child has had. I think that can just send parents into a real panic mode because they feel like there should be joined up information." (04)

Participants also discussed their perceptions of what happens to families at discharge, in terms of planning that happens prior to discharge, the practicalities at the time of discharge and communication with local health professionals. In particular, staff described the lack of consistency in discharge planning and the impact on families of a poorly planned discharge. A number of staff identified processes which they thought worked and didn't work for families 
once they were back home, which primarily focused on the processes of communication and keeping the family engaged with services.

"...the last call I had from a family couldn't be worse. Because they were suddenly discharged. They didn't think they were going for another 3 days, and they suddenly went and they didn't have any mechanisms in place at all at that point in time.

There's a newborn baby... and they had to travel so they weren't where their family were. So I would suggest that that one failed miserably....and they were really upset, I mean REALLY upset. Nobody knew that they were going home, they didn't know they were going home and it was all rushed and they were frightened." (06)

\section{Role of helpline staff and the helpline}

Helpline staff talked a lot about their own role and the role of the helpline. In particular they described the difficulty they have when parents call seeking medical advice when they are not in a position to provide that advice and their own anxieties around that. They expressed the tension they experience between wanting to reassure parents but at the same time not giving them false assurances.

"Things that parents sometimes say "I don't know if this is normal or not" something I hear a lot "Is this normal?" and of course you can't answer that. You don't want to say "oh that's fine" because something might happen to them and you don't want to panic them and say "Go to A\&E". When I try and say take them to $A$ \&E you have to say it so calmly. There are certain times that you think why are the parents phoning a charity when they should be phoning a medical professional. That's what worries me. Why are they phoning us - they should be phoning ...or taking their child to a doctor." $(01)$

This article is protected by copyright. All rights reserved. 
They also talked about their role in facilitating communication between professionals and families. For example, one participant described their role in developing links with centres, sometimes with a view to giving more specific information to families.

"We work as hard as we can to make links really firm with centres because that really helps us. A lot of times we might ring cardiac liaison nurses or doctors ourselves and ask them about helpline calls if we had a particularly difficult one come in and we feel the parents won't make that contact themselves." (04)

Others talked about the advice they provide to parents to enable them to talk to health professionals, recognising that as helpline staff they are not able to provide the answers to parents' medical questions but that they can have a role in facilitating communication.

"We're often giving people advice on how to speak to their cardiologists because more often than not, and I completely understand, you go in to speak to someone and just sit there and get completely overwhelmed by what you're listening to and not understanding what they're saying and then leave with more questions......So what we try and do is prepare people before they see the cardiologists - try and get them to write down all the questions they're asking us, try and get them to write down all of those questions because again we can't answer them." (01)

"Quite a bit of my time on the phone is spent helping people to see that to get what they want they are going to have to stamp their feet and make a nuisance of themselves because it won't be offered up on a plate." (02)

Parents' levels of confidence was also mentioned by some of the participants in relation to how parents interacted with health professionals and the role of help-line staff in empowering parents.

This article is protected by copyright. All rights reserved. 
"When I take those types of calls I view that as a way of giving parents....the permission or confidence if you like to go back and ask questions.... They're not stupid questions and how about raising it like this, this and this". (05)

Finally, some also commented on specific aspects such as social media and the need for them to be aware of what is being posted and to take action if necessary:

"Sometimes you are a bit worried about the information that is given and we try to step in. So we try to monitor that." (03)

\section{Discussion}

As far as we are aware, this is the first study which has specifically looked at the perceptions of charity helpline staff about their contact with parents of children with CHD. Important, previously invisible, data were captured about the needs of infants and their parents following hospital discharge, offering new insight and characterising an important feedback loop about, and into, the system of care for these infants and families. They provided a unique perspective on the issues faced by parents taking children home after cardiac surgery and identified a number of examples of when things work and don't work for families. They also had a wealth of collective experience of multiple contacts with many families which informed their views and understanding of the factors that had an impact on families' needs. Knowledge, communication and support are clearly key elements for families and those working with them and the insights of the helpline staff provide evidence to inform the development of more structured interventions to optimise support for children and their parents.

This article is protected by copyright. All rights reserved. 
The overarching factor described throughout all of the interviews was a lack of consistency in the way that families are supported after discharge from hospital, both in terms of their information and psychosocial needs. Families themselves clearly have different needs but the ways in which support was provided and their needs addressed varied enormously from family to family, despite many similarities in the patient journey for infants undergoing cardiac surgery. This variability was perceived to exist in all areas of care, both in terms of the place of care (tertiary, secondary or primary) and the professionals providing it (with respect to both individuals and generic professional groups). Helpline staff articulated many examples of good communication and provision of knowledge by health professionals but also identified many examples where families had been failed or support had been less than optimal, however unintentional that might have been. Furthermore, as well as identifying inconsistencies in the way families are supported after discharge, participants also described examples of poor service delivery, particularly in relation to discharge planning. There is clearly national variation in the way in which services are delivered by the cardiac centres and in primary and secondary care and our findings have clear implications for practice and highlight the importance of agreed national standards.

This study identified some specific functions fulfilled by helpline staff above and beyond providing support and information and signposting families to appropriate resources, For example, they talked about providing equipment for families but this was rarely because a family had not been given a necessary piece of equipment by the hospital. Rather, it appeared that helpline staff were recognizing that parents were understandably anxious about caring for their infant at home and were putting in place solutions for managing that anxiety. There was no sense that hospitals had failed to send families home with vital monitoring equipment, rather the view was that parents did not know what to look out for and a machine measuring oxygen saturations, for example, was a practical way of helping them identify important signs of deterioration, which in turn helped them to feel less anxious.

This article is protected by copyright. All rights reserved. 
Although not explored in this study, provision of equipment by a helpline could have implications for health service resources - for example, parents may act more quickly if their baby is deteriorating or alternatively feel more reassured that their baby is well, with either scenario resulting in more appropriate use of health care. Participants also identified that their role included elements of family advocacy if they thought that parents may not contact the cardiac team in situations where it seemed necessary. In such situations they described how they called the cardiac team to inform them of their concerns about a child or family so that the team could initiate contact - an element of their role which is likely to be underacknowledged but clearly valuable and potentially critical to the wellbeing of the infant.

\section{Limitations}

There are some limitations to the overall study. Firstly, although four of the charities providing support to families were involved, the overall number of participants was small. The four organisations provide support in different ways and their access to specialised medical knowledge varies. Participants from three of the groups provide support to specific patient groups whereas the remainder are there for a generic heart population covering the whole CHD spectrum. Participants could also only comment on the support and information needs of families who contacted the helpline, which is likely to result in the needs of some parents not being represented, such as those of parents from non-English speaking populations or parents who were less able - for financial, social or other reasons - to contact the helpline. From previous work (17) we know that children from ethnic minorities are over-represented in the CHD population and yet these are the families who are least likely to access support. A further limitation was that not every participant had experience in each of the areas covered by the interview - for example, one helpline staff member had not taken any calls in relation to discharge after surgery but they had spoken to many parents about sources of support once families were back home. We did not have information about how many calls each participant took each year, which may have provided more insight into

This article is protected by copyright. All rights reserved. 
whether and how the number of families that helpline staff spoke to influenced their perceptions. Finally, parents invariably call a helpline because they have a problem so the views expressed by the helpline staff are inevitably skewed towards the things that do not work or have gone wrong for families, with helpline staff having less information and examples of systems of care that work well.

Despite these limitations, there are a number of unique elements with the approach adopted in the study. The helpline staff are part of national charities and are therefore in contact with families from all over the UK, rather than only being exposed to families from a limited number of specialist cardiac centres. They do not have affiliations with any individual centre and whilst individual helpline staff will inevitably hold opinions about aspects of care in specific cardiac centres, they were providing us with a national overview. Furthermore, charities do not provide clinical care and in most cases helpline staff are not medically trained, thus reducing the likelihood of medical or clinical bias influencing their responses.

The views of the helpline staff we interviewed provide important and previously un-captured evidence to help inform and develop interventions, such as enhancing parents' communication skills (23), to better support children and families after hospital discharge following infant cardiac surgery. Helpline staff have an important role in supporting and facilitating communication, both in terms of speaking to families about how to talk to professionals as well as talking to professionals directly to get or give information when parents are unable to do so, which in turn should improve professionals' understanding of parent concerns and their communication with parents. Thus, capturing the perspective of helpline staff about communication issues has also highlighted the need for interventions with professionals as well as parents. The findings from this study have contributed, through a comprehensive evidence synthesis including interviews with parents and health 
professionals, to a series of evidence-based recommendations for improving the discharge and post-discharge care of infants following cardiac surgery, reported elsewhere.(18)

\section{Conclusion}

Previous research into the role of helplines in health care has focused on the user perspective, involving interviews or surveys with callers rather than with the helpline staff. We focused instead on accessing information about families' needs and their experiences of using services by tapping into the staff's body of experience. Interviews with helpline staff indicated that parents' reasons for calling charity helplines were multifaceted, with their psychosocial needs being intertwined with their needs for information and advice. Furthermore, the perceptions of helpline staff about communication issues highlighted the need for interventions with professionals as well as with parents.

\section{Acknowledgements}

Contributors: This paper is submitted on behalf of the Infant Heart Study team (NIHR Project number: 10/2002/29).

The authors confirm all patient/personal identifiers have been removed or disguised so the patient/person(s) described are not identifiable and cannot be identified through the details of the story.

\section{Competing interests}

None

This article is protected by copyright. All rights reserved. 


\section{Funding}

This project was funded by the National Institute for Health Research Health Services and

Delivery Research programme (Project No: 10/2002/29). The views and opinions expressed therein are those of the authors and do not necessarily reflect those of the NIHR HS\&DR programme or the Department of Health.

Abbreviations

CHD - congenital heart disease

CHF - Children's Heart Federation

UK - United Kingdom

\section{References}

1. Reubsaet A, Lechner L, De Vries H. The Dutch cancer information helpline: more critical patients after 10 years. Patient education and counseling 2006; 63:215-22

2. Hardyman R, Hardy P, Brodie J, Stephens R. It's good to talk: comparison of a telephone helpline and website for cancer information. Patient education and counseling 2005; 57:315-20

3. Ekberg K, McDermott J, Moynihan C, Brindle L, Little P, Leydon GM. The role of helplines in cancer care: intertwining emotional support with information or advice-seeking needs. Journal of psychosocial oncology 2014; 32:359-81

4. Collett A, Kent W, Swain S. The role of a telephone helpline in provision of patient information. Nursing Standard 2006; 20:41-4

5. Venn M, Darling E, Dickens C, Slevin M, Quine L, Rutter D. The experience and impact of contacting a cancer information service. European Journal of Cancer Care 1996; 5:38-42

6. Shaw J, Young J, Butow P, Chambers S, O'Brien L, Solomon M. Delivery of telephonebased supportive care to people with cancer: An analysis of cancer helpline operator and cancer nurse communication. Patient education and counseling 2013; 93:444-50

7. Leydon GM, Ekberg K, Drew P. "How can I help?" Nurse call openings on a cancer helpline and implications for call progressivity. Patient education and counseling 2013; 92:23-30

This article is protected by copyright. All rights reserved. 
8. Hoffman JI, Kaplan S. The incidence of congenital heart disease. Journal of the American College of Cardiology 2002; 39:1890-900

9. Marino BS, Bird GL, Wernovsky G. Diagnosis and management of the newborn with suspected congenital heart disease. Clinics in perinatology 2001; 28:91-136

10. Franich-Ray C, Bright MA, Anderson V, Northam E, Cochrane A, Menahem S, et al. Trauma reactions in mothers and fathers after their infant's cardiac surgery. Journal of pediatric psychology 2013; 38:494-505

11. Hearps SJ, McCarthy MC, Muscara F, Hearps SJ, Burke K, Jones B, et al. Psychosocial risk in families of infants undergoing surgery for a serious congenital heart disease. Cardiology in the young 2014; 24:632-9

12. Jackson AC, Frydenberg E, Liang RP, Higgins RO, Murphy BM. Familial impact and coping with child heart disease: a systematic review. Pediatric cardiology 2015; 36:695-712

13. Wei H, Roscigno CI, Hanson CC, Swanson KM. Families of children with congenital heart disease: A literature review. Heart \& lung : the journal of critical care 2015; 44:494-511

14. Woolf-King SE, Anger A, Arnold EA, Weiss SJ, Teitel D. Mental Health Among Parents of Children With Critical Congenital Heart Defects: A Systematic Review. Journal of the American Heart Association 2017; 6:e004862

15. Tregay J, Brown KL, Crowe S, Bull C, Knowles RL, Smith L, et al. Signs of deterioration in infants discharged home following congenital heart surgery in the first year of life: a qualitative study. Archives of disease in childhood 2016; 101:902-8

16. Tregay J, Wray J, Bull C, Franklin RC, Daubeney P, Barron DJ, et al. Unexpected deaths and unplanned re-admissions in infants discharged home after cardiac surgery: a systematic review of potential risk factors. Cardiology in the young 2015; 25:839-52

17. Knowles R, Ridout D, Crowe S, Bull C, Wray J, Tregay J, et al. Ethnic and socioeconomic variation in incidence of congenital heart defects. Archives of disease in childhood 2017; 102:496-502

18. Crowe S, Knowles R, Wray J, Tregay J, Ridout DA, Utley M, et al. Identifying improvements to complex pathways: evidence synthesis and stakeholder engagement in infant congenital heart disease. BMJ open 2016; 6:e010363

19. Tregay J, Brown K, Crowe S, Bull C, Knowles R, Wray J. I was so worried about every drop of milk. feeding problems at home are a significant concern for parents after major heart surgery in infancy Matern Child Nutr 2016; 1740:8709

20. Crowe S, Ridout DA, Knowles R, Tregay J, Wray J, Barron DJ, et al. Death and emergency readmission of infants discharged after interventions for congenital heart disease: a national study of 7643 infants to inform service improvement. Journal of the American Heart Association 2016; 5:e003369

21. Tregay J, Wray J, Crowe S, Knowles R, Daubeney P, Franklin R, et al. Going home after infant cardiac surgery: a UK qualitative study. Archives of disease in childhood 2016; 101:320-5

This article is protected by copyright. All rights reserved. 
22. Srivastava A, Thomson SB. Framework Analysis: A Qualitative Methodology for Applied Policy Research. Journal of Administration and Governance 2009; 4:72-9

23. Jackson AC, Liang RPT, Frydenberg E, Higgins RO, Murphy BM. Parent education programmes for special health care needs children: a systematic review. Journal of clinical nursing 2016; 25:1528-47

Figure caption: Factors which influence the knowledge, communication and support needs of families and the way in which helpline staff perceive those needs

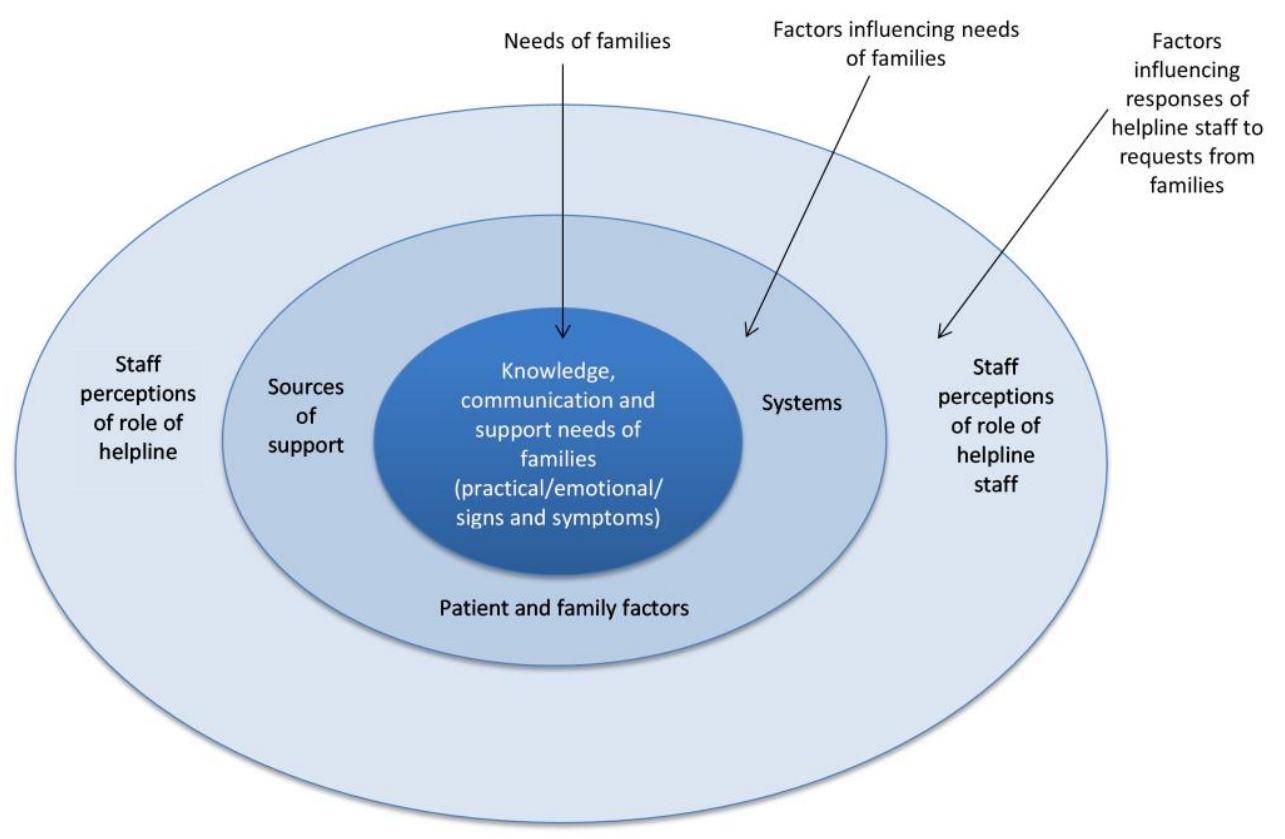

This article is protected by copyright. All rights reserved. 